\title{
Study of Soil Erosion at a Site near Chemical Engineering Laboratory in UNIMAS
}

\author{
Fizzahutiah Binti Taha ${ }^{1}$ and Shenbaga R. Kaniraj ${ }^{2}$
}

\begin{abstract}
Soil erosion is one of the problems of environmental concern. Natural causes such as rainfall and human development activities are the two main factors that can cause soil erosion. In order to control soil erosion, especially in urban areas, the bare soil surface needs to be covered by plants as much as possible. Re-vegetation, the best permanent erosion control measure, might take time to be complete. Therefore, some suitable temporary measures should be applied to minimize the amount of soil loss. Topographical features and climate are among the factors that determine the amount of soil erosion. In order to control the rate of erosion, it is important to estimate the amount of soil loss. Universal Soil Loss Equation (USLE) is one of the approaches to estimate the rate of soil loss. In this study, the topographical features of a site prone to erosion within University Malaysia Sarawak (UNIMAS), were investigated by field survey. Laboratory experiments were carried out on soil samples collected from the site. The parameters for use in USLE were evaluated. The soil loss at the site in 2011 was estimated as $52.85 \mathrm{t} \mathrm{ha}^{-1}$ and the soil erosion risk at the site was categorized as moderately high.
\end{abstract}

Keywords: environmental issues, soil erosion, topographical features, Universal Soil Loss Equation (USLE), urban area

\section{INTRODUCTION}

U

RBAN areas have high potential for soil erosion due to developmental activities . The environmental impact due to soil erosion includes clogged drains, increased flooding, land degradation, etc. In order to minimize soil erosion, erosion risk analysis should be carried out. There are various techniques to analyze erosion risk. The most widely used mathematical model to estimate soil loss from an area is the Universal Soil Loss Equation (USLE). In Malaysia, USLE is commonly used in Environmental Impact Assessments (EIA) for predicting erosion and soil loss from land development sites [1].

Soil erosion is the removal of soil particles by wind, gravity, mass movement and water. There are many agents of erosion, but the most significant agent for soil erosion in the Malaysian environment is water. This is due to the high annual rainfall and storm events in Malaysia. The amount of soil loss will speed up in a short amount of time on the bare soil surface. Exposed soil surface will also increase the frequency of flood flows which will result in increased erosion and higher sediment concentration.

The most common soil erosion in Malaysia is rain splash erosion. Bare soil surface is extremely susceptible to rain splash erosion. Rain splash erosion occurs during high intensity rainstorms; the force of the falling raindrops dislodges the soil particles. Sheet erosion, rill erosion and gully erosion are the other common types of erosion. Sheet erosion, also known as inter-rill erosion, is the lateral transportation of loose soil in a uniform layer. Sheet erosion occurring during heavy rain can be interrupted by vegetation. Rill erosion results in the formation of shallow drainage lines particularly on short and steep slopes. Gully erosion occurs at sites of unstable exposed surfaces with high intensity rainfall producing high runoff rates. Gully erosion produces deeper and larger flow channels compared to rill erosion [1].

The amount of soil loss due to erosion is affected by soil characteristics, topography, climate and other factors. Soil texture, organic matter, moisture content and soil structure are the soil characteristics that affect the detachment and removal of the soil particles. Topographical features affecting the erosion rate are the gradient of slope, length of slope, elevation, and size and shape of the watershed. In steeper and longer slopes, higher runoff and soil erosion will occur. Annual rainfall is one of the climate factors that affect the amount of soil loss. Higher precipitation increases the amount of soil loss particularly on bare soil surfaces.

\section{II.METHODOLOGY}

The study explained in the paper was carried out at a site within UNIMAS, Kota Samarahan. The population of Kota Samarahan from the 2010 census was 87,923 . As the population is more than 10,000 , Kota Samarahan is classified as an urban area. Several areas in UNIMAS are experiencing soil erosion. However, most of them are not serious. But, there is serious soil erosion at one particular site near the Chemical Engineering Laboratory. Therefore, this site was chosen for the study. Figure 1 shows the location of the site in plan. Figure 2 shows the view of the site and the structures nearby.

${ }^{1}$ Fizzahutia Binti Taha is with the University College of Science and Technology, 96000 Sibu, Sarawak, Malaysia. She was a student in the Faculty of Engineering, Universiti Malaysia Sarawak, 94300 Kota Samarahan, Sarawak, Malaysia. (e-mail: switjan_0101@yahoo.com.my; phone: +6084 311 888 Ext 116; fax: +6084 322 323).

${ }^{2}$ S. R. Kaniraj, is with the Faculty of Engineering, Universiti Malaysia Sarawak, 94300 Kota Samarahan, Sarawak, Malaysia. (e-mail: rkjshenbaga@feng.unimas.my) 


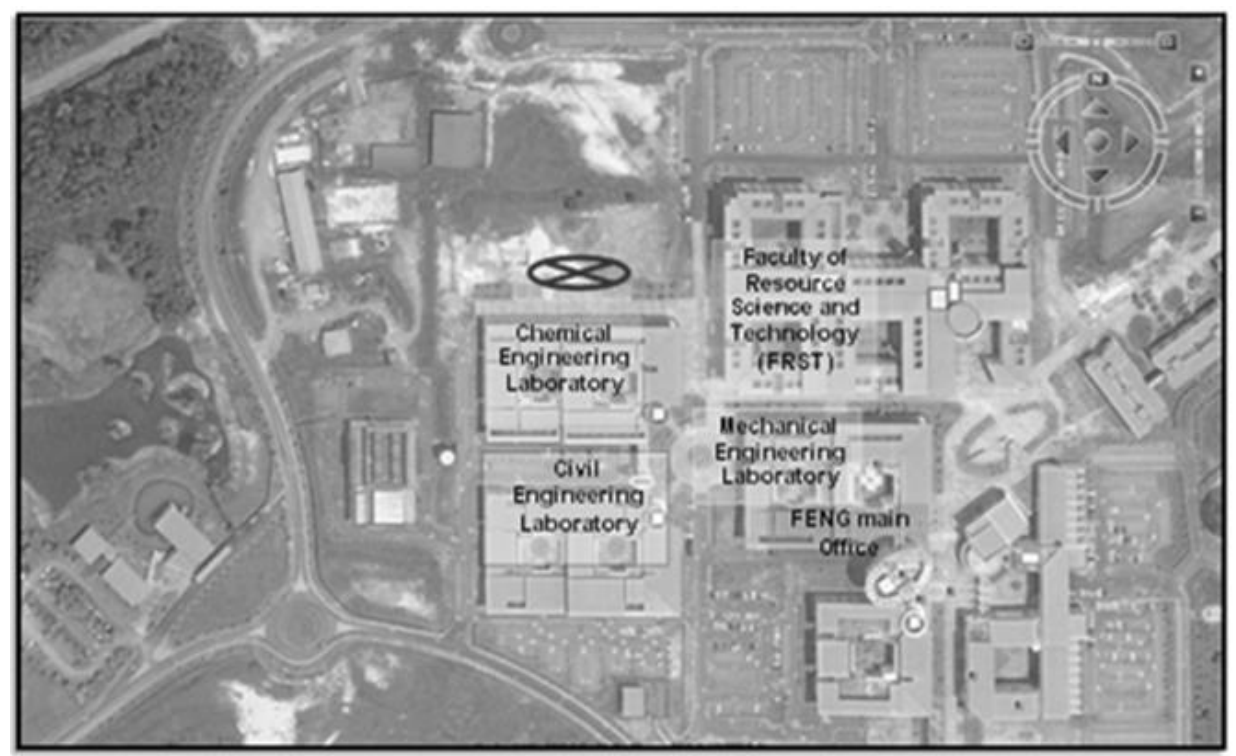

Figure 1: Study Site of Soil Erosion in UNIMAS

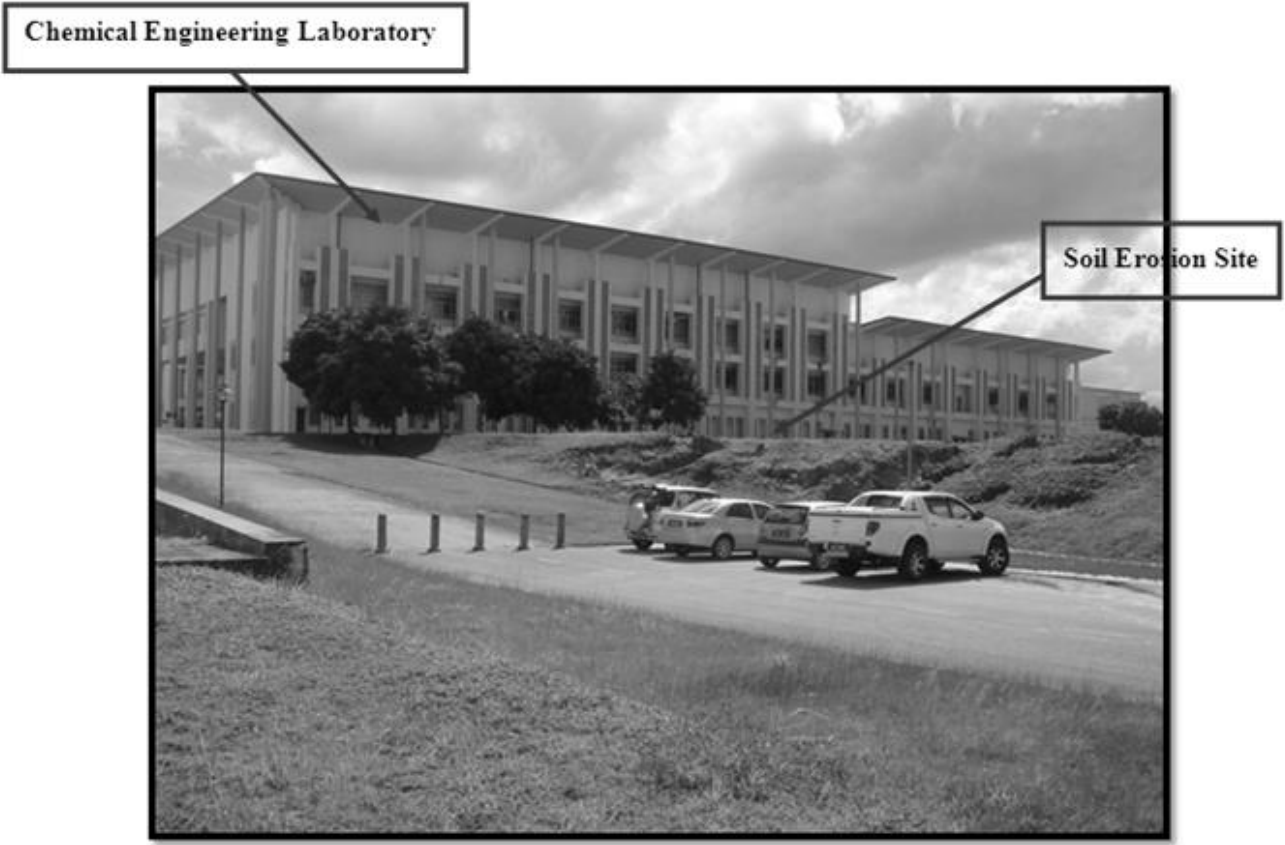

Figure 2: Soil Erosion Site Adjacent to the Chemical Engineering Laboratory

It was observed that the type of erosion at this site was gully erosion. Many deep and large flow channels were present in this area (Figure 3). The erosion in this area was associated with unstable exposed soil surfaces, high intensity rainfall events, and high runoff rates. The eroded soil was transported into the concrete drains. The concrete drains near this area were mostly choked with sediments (Figure 4). As a result, the efficiency of the drainage system had been affected and flooding occurred easily the vicinity of this area.

The soil erosion process at this site might have started with rain splash erosion. Since there were no measures for erosion control implemented at the site, the rain splash erosion eventually became gully erosion. Erosion and sedimentation result in depletion of river aquatic life and also affect the marine ecology as large sediment loads deposited along the coastline smother breeding grounds and coastal sea-beds. Inland, the sediments choke up culverts, river-beds and the drainage system. This will result in the increase in frequency of flash floods. Thus, there is a need to design and review an Erosion and Sediment Control Plan (ESCP) and supervise the implementation of Best Management Practices (BMPs) on-site. An integrated approach shown in Figure 5 was used to achieve the objective of the study systematically.

The amount of soil loss was estimated using USLE (Equation 1). Necessary field tests and site inspection were conducted to identify the USLE parameters for estimating the amount of soil loss at the site. Sieve analysis test was conducted to classify the soil at the site (type of soil, organic matter, size and percentage of different soil particles, etc.). To identify the topographical features of the site, namely, slope steepness and length of the slope, field surveying (leveling) was conducted. Others data such as, the annual precipitation at the site, were collected from the Department of Irrigation and Drainage 
(DID), Kota Samarahan.

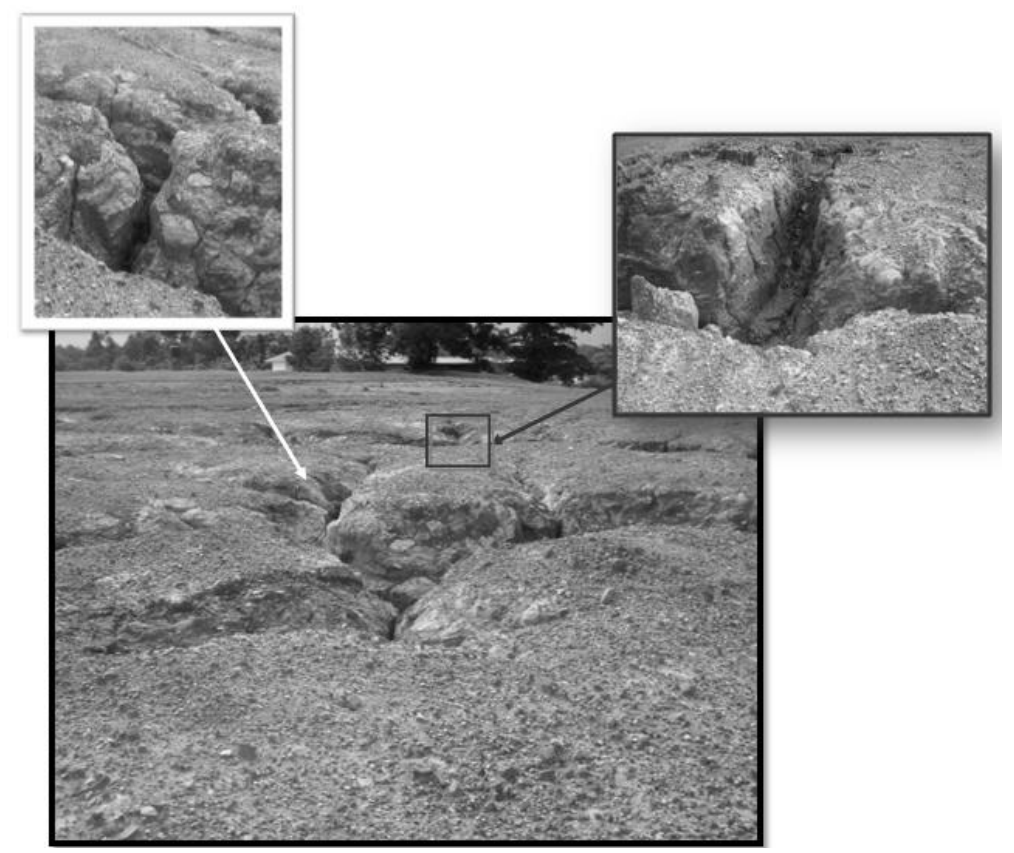

Figure 3: Gully Erosion at the Site near the Chemical Engineering Laboratory

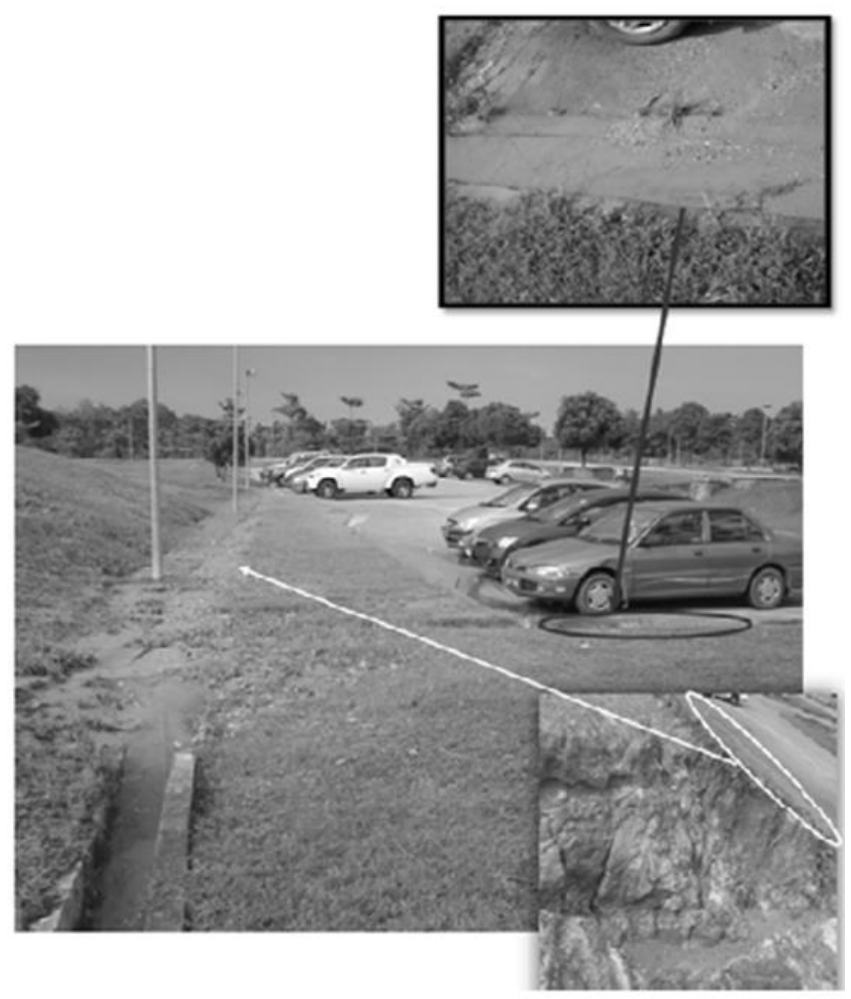

Figure 4: Concrete Drains Choked with Sediments

In Eq. 1, $A=$ mean annual soil loss $\left(\mathrm{t} \mathrm{ha}^{-1}\right), R=$ rainfall erosivity index $\left(\mathrm{Mg} \mathrm{mm} \mathrm{ha}{ }^{-1} \mathrm{~h}^{-1}\right), K=$ soil erodibility factor, $L S=$ topographical feature, $C=$ cropping management factor, and $P=$ erosion control management factor. Rainfall erosivity index $(R)$ represents the erosion potential of rainstorms to be expected in a given locality. It is related to the kinetic energy and intensity of the rain. The product $E I_{30}$ reflects the potential ability of rain to cause erosion, where $E=$ total kinetic energy of rain, and $I_{30}=$ peak 30 minutes intensity [2]. The equations suggested by Roose [1] and Morgan [3] to estimate $R$ are shown in Equations 2 and 3, respectively. 
UNIMAS e-Journal of Civil Engineering: Volume 4, Issue 2

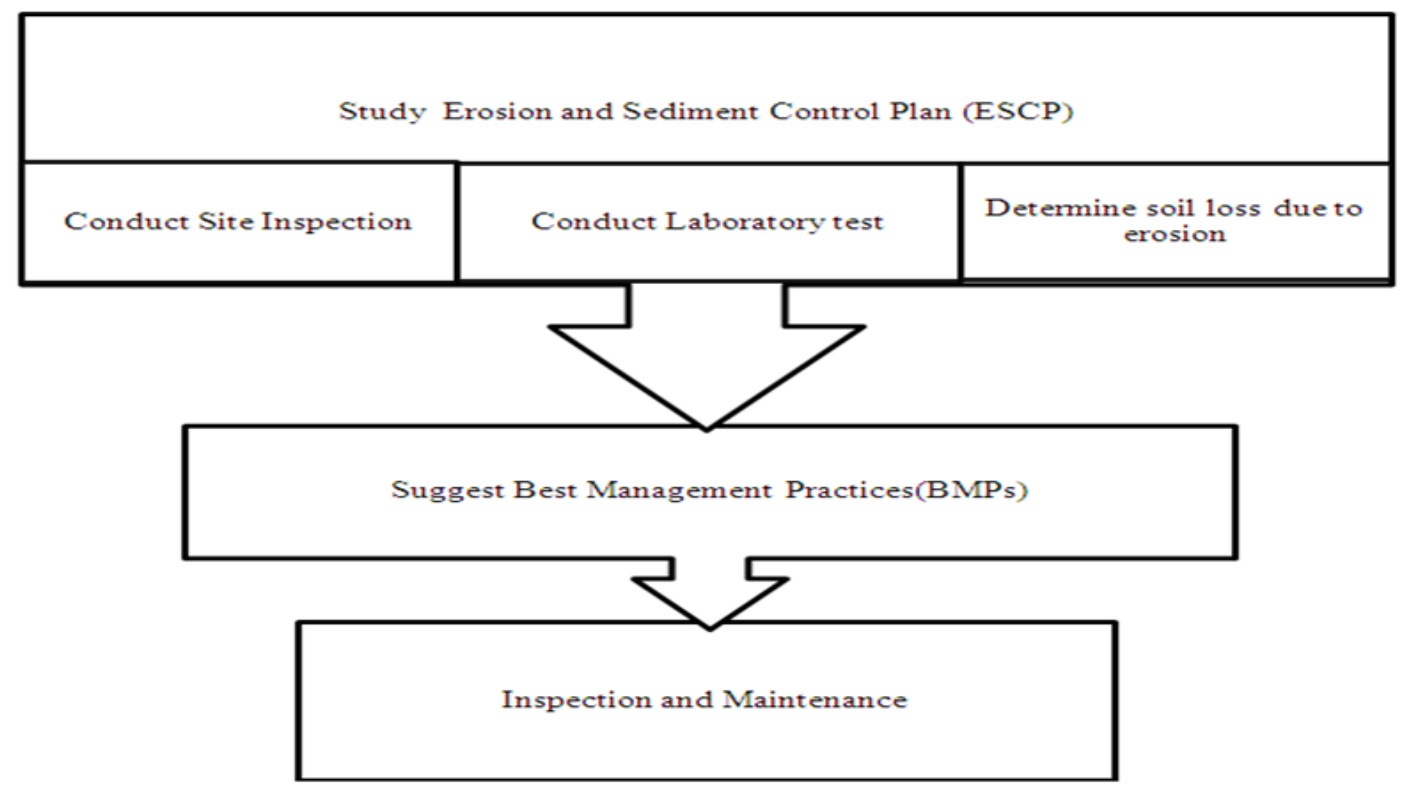

Figure 5: Flow Chart for Study of Controlling and Managing Erosion in Urban Areas

$R=\left(E I_{30}\right) / 100$

In Equation 2, $R$ is in $\left(\mathrm{Mg} \mathrm{mm} \mathrm{ha}^{-1} \mathrm{~h}^{-1}\right), E=$ total kinetic energy of rain $(E=9.28 p-8838), p=$ mean annual precipitation $(\mathrm{mm})$, and $I_{30}=$ peak 30 minutes intensity $\left(75 \mathrm{~mm} \mathrm{~h}^{-1}\right)$.

$R=p \times 0.5 \times 17.3$

In Equation 3, $R$ is in $\left(\mathrm{Mg} \mathrm{mm} \mathrm{ha}{ }^{-1} \mathrm{~h}^{-1}\right)$, and $p=$ mean annual precipitation $(\mathrm{mm})$. Soil erodibility factor, $K$, is the ability of the soil to be eroded by flowing water. It depends on the soil structure, organic matter, size composition of the soil particles, and soil permeability measured as hydraulic conductivity. The value of $K$ can be obtained using a nomograph shown in Fig. 6 $[4,5]$.

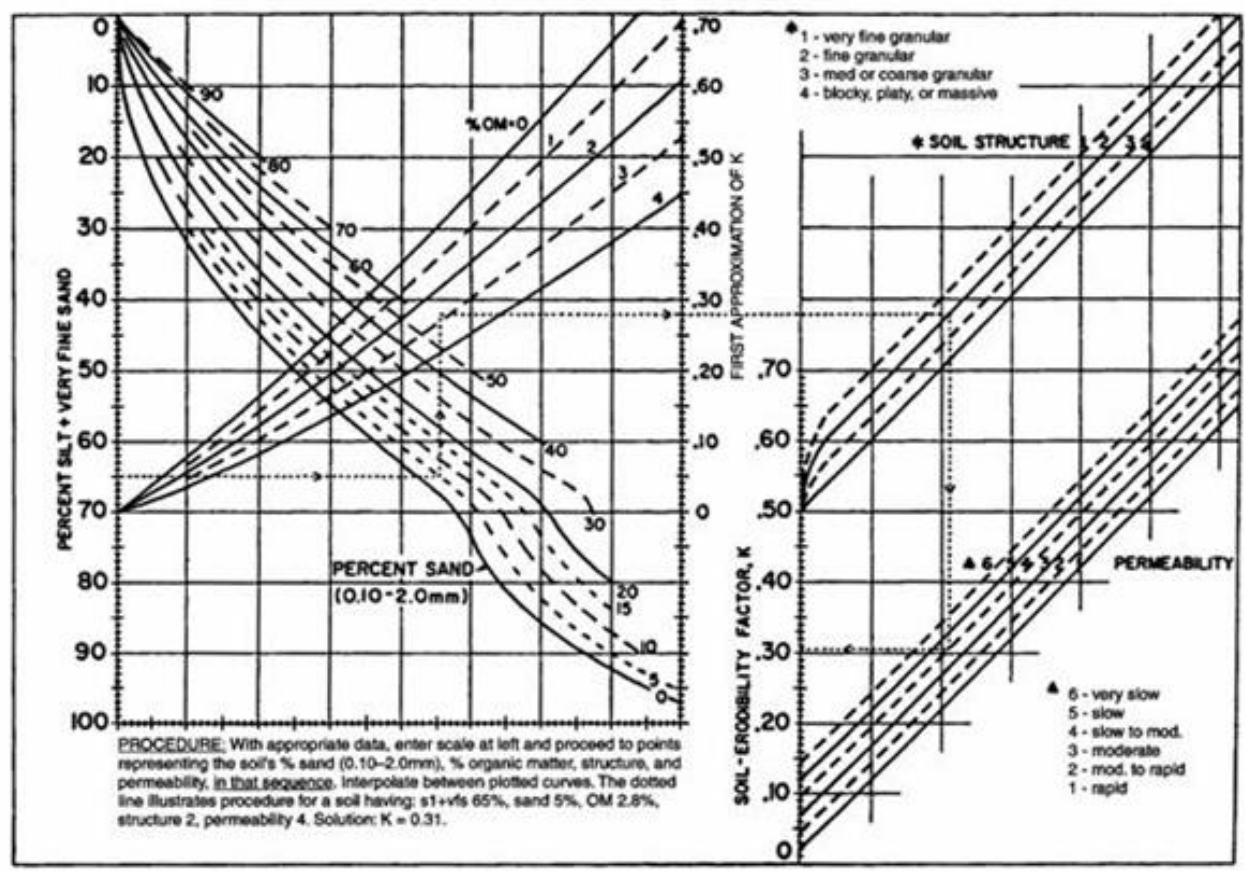

Figure 6: Nomograph for Soil Erodibility Factor, $K[4,5]$

The value of topographical features factor, $L S$, can be obtained either by Equation 4 or by using a nomograph shown in Fig. 7 [6].

$L S=\left(0.065+0.045 s+0.0065 s^{2}\right) x(l / 22)^{0.5}$

In Equation $4, l=$ length of the sloping ground $(\mathrm{m})$, and $s=$ slope gradient $(\%)$. Cropping management factor, $C$, and 
UNIMAS e-Journal of Civil Engineering: Volume 4, Issue 2

erosion control management factor, $P$, are estimated according to the site characteristics by site inspection. Table 1 shows the summary of parameters in USLE and from where the values can be obtained.

Table 1: Sources for values of USLE parameters

\begin{tabular}{|c|c|}
\hline USLE parameters & Sources \\
\hline Rainfall erosivity index, $R$ & $\begin{array}{l}\text { Site inspection and related parties (e.g. DID, Meteorology department) } \\
\text { - Precipitation value }\end{array}$ \\
\hline Soil Erodibility factor, $K$ & $\begin{array}{l}\text { Nomograph (Fig. 6) and laboratory tests for: } \\
\text { - Grain sizes in soil mass } \\
\text { - Organic matter in soil }\end{array}$ \\
\hline Topographical factor, $L S$ & $\begin{array}{l}\text { Nomograph (Fig. 7) and site survey (leveling) } \\
\text { - Slope steepness } \\
\text { - Slope length }\end{array}$ \\
\hline Cropping management factor, $C$ & $\begin{array}{l}\text { Site inspection } \\
\text { - Practice applied on the selected area }\end{array}$ \\
\hline Erosion control management factor, $P$ & $\begin{array}{l}\text { Site inspection } \\
\text { - Topographical information } \\
\text { - Slope steepness }\end{array}$ \\
\hline
\end{tabular}

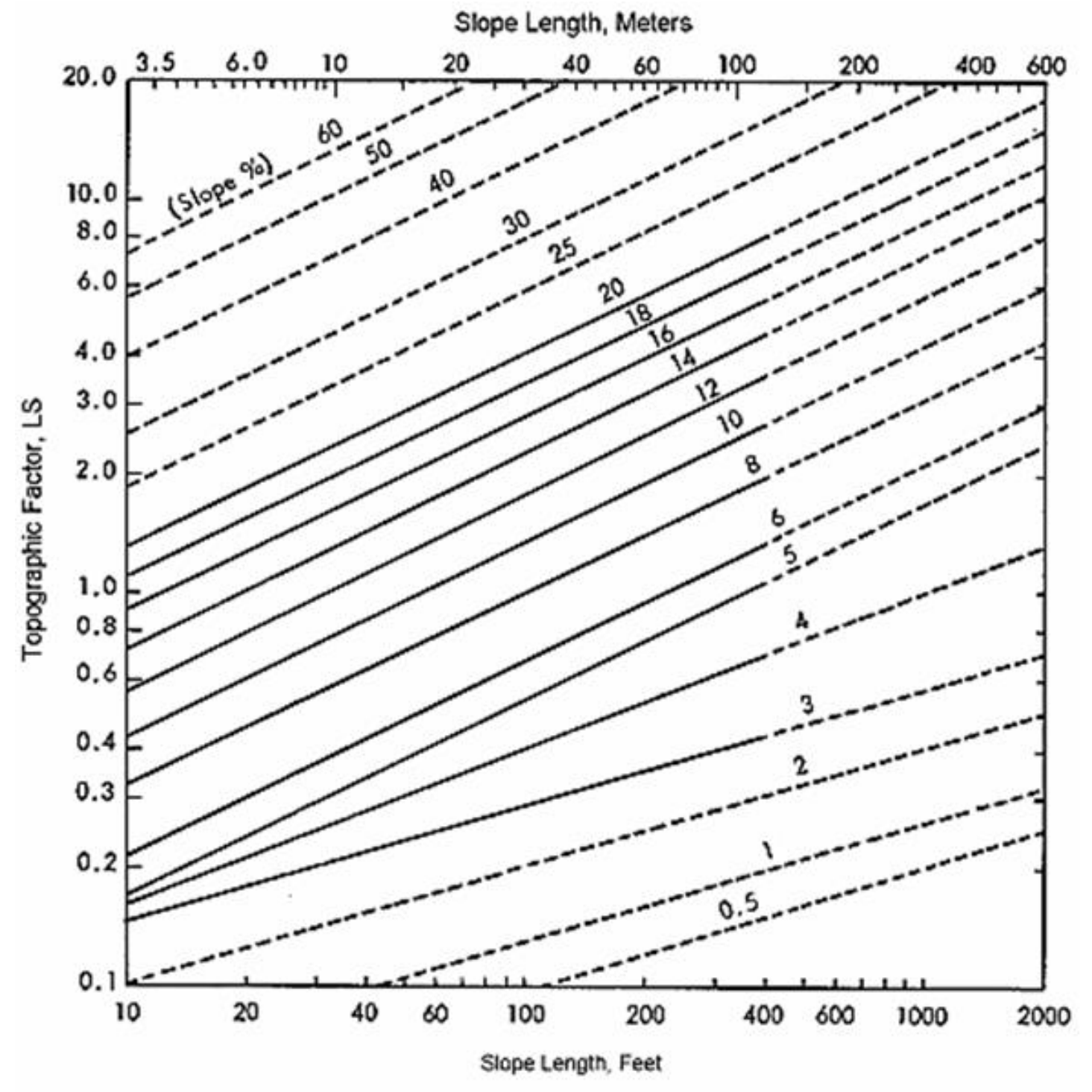

Dashed lines represent estimates for slope dimensions beyond the range $\alpha$ lengths and slecpnesses for which data are available

Figure 7: Nomograph for Topographic Factor, $L S[6]$ 


\section{RESULTS, ANALYSIS AND DISCUSSION}

The amount of soil loss at the site was estimated using USLE. For rainfall erosivity index, $R$, the important data needed is the mean annual precipitation. The data for precipitation were taken from Department of Irrigation and Drainage (DID). In 2011, the precipitation at the site was about $4584.5 \mathrm{~mm}$. The average value of $R$ for the site from Equations 2 and 3 was $32467.8 \mathrm{Mg} \mathrm{mm} \mathrm{ha}^{-1} \mathrm{~h}^{-1}$.

To determine soil erodibility factor, $K$, first sieve analysis test and organic content test were carried out in the laboratory on soil samples collected from the site. The type of soil at the site was poorly graded sand, SP. The organic content from loss-on-ignition method was $2.3 \%$. The soil structure was medium granular and the permeability for this soil was rapid. Using all these data on the nomograph in Fig. 6, the value of $K$ was estimated as 0.013 .

From field survey, the slope length, $l$, and slope steepness, $s$, were estimated as $23.8 \mathrm{~m}$ and $2.27 \%$, respectively. The value of topographic factor, $L S$, from both Equation 4 and nomograph in Fig. 7 was estimated as 0.21 . Based on the field inspection, the cropping management factor, $C$, and erosion control practice factor, $P$, for the site were assigned as 1 and 0.6 , respectively. Using the USLE parameters in USLE the amount of soil loss at the site in 2011 was estimated as $52.85 \mathrm{t}^{-1}$. Based on the criteria of Department of Agriculture [7] the soil erosion risk at the site was classified as moderately high.

Since the soil erosion risk is moderately high, proper management and controlling of erosion should be planned. To manage erosion, it is important to identify the suitable erosion and sediment controls for the site. These controls are based on the condition of soil loss, types of soil, topographical features, location of erosion, and the surrounding activities. The 9 steps for developing and implementing an erosion and sediment control plan are: $a$ ) identification of issues and concerns, $b$ ) development of goals and objectives, $c$ ) collection and analysis of data, $d$ ) development of BMP selection criteria, $e$ ) nomination of candidate BMPs, $f$ ) screening and selection of BMPs, $g$ ) development of ESPC, $h$ ) operation, monitoring, and maintaining the system, and $i$ ) updating the plan [6]. For selecting the best management practices (BMPs), the 5 recommended criteria are: $a$ ) temporary vs. permanent BMPs, $b$ ) availability, $c$ ) feasibility, $d$ ) suitability for the site, and e) cost effectiveness.

\section{CONCLUSION}

The paper presents the study of erosion risk at a site in UNIMAS near Chemical Engineering Laboratory. The USLE parameters were determined and the amount of soil loss at the site was estimated using USLE. The amount of soil loss at the site in 2011 was estimated as $52.85 \mathrm{t} \mathrm{ha}^{-1}$ and categorized as moderately high risk erosion.

The environment impact due to the soil loss was the failure of drainage system at the site. The concrete drains at the roadside were fully choked with sediments. The parking spaces adjacent to the site area needed to be closed since the eroded soil had spread to the parking areas. In order to control erosion at the site, 9 important key steps of ESCP and 5 criteria for selection of BMPs had been outlined.

\section{ACKNOWLEDGMENT}

The authors express their gratitude to Universiti Malaysia Sarawak for the support to this research.

\section{REFERENCES}

[1] Department of Environment, Guidelines for Prevention and Control of Soil Erosion and Siltation in Malaysia. Department of Environment, Ministry of Science, Technology and Environment, Malaysia, 1996.

[2] S. I. Mir, M. B. Gasim, S. A. Rahim, and M. E. Toriman, "Soil loss assessment in the Tasik Chini catchment, Pahang, Malaysia," Geological Society of Malaysia, pp. 1-7, 2010.

[3] R. P. C. Morgan, Soil Conservation Problems and Prospects. John Wiley \& Sons Ltd, Toronto, 1980.

[4] R. Morgan, Soil Erosion and Conservation. Australia: Blackwell Science Ltd, 2005.

[5] "Erosion Mechanisms and the Revised Universal Soil Loss Equation (RUSLE)," Retrieved September 9, 2013, from http://rpitt.eng.ua.edu/Class/Erosioncontrol/Module3/Module3.htm

[6] "Universal Soil Loss Equation: (Wischmeier and Smith)," (n.d.). Retrieved November 17, 2011, from http://www.evsc.virginia.edu/ alm7d/soils/handouts/USLE.pdf

[7] "Soil Erosion Risk Map of Peninsular Malaysia," Department of Agriculture, Retrieved September 9, 2013, from http://www.doa.gov.my/documents/10157/2ba95366-5f8a-416d-ae90-9fb016fa26eb 